\title{
Divergent Photocyclization/1,4-Sigmatropic Rearrangements for the Synthesis of Sesquiterpenoid Derivatives
}

\author{
Evgueni Gorobets, ${ }^{\dagger}$ Norman E. Wong, ${ }^{\dagger}$ Robert S. Paton, ${ }^{\dagger}$ Darren J. Derksen ${ }^{\dagger *}$ \\ 'Department of Chemistry, University of Calgary, 2500 University Drive NW, Calgary, Alberta, Canada T2N 1N4. \\ *Chemistry Research Laboratory, Oxford University, Mansfield Road, Oxford OX1 3TA, UK
}

Supporting Information Placeholder

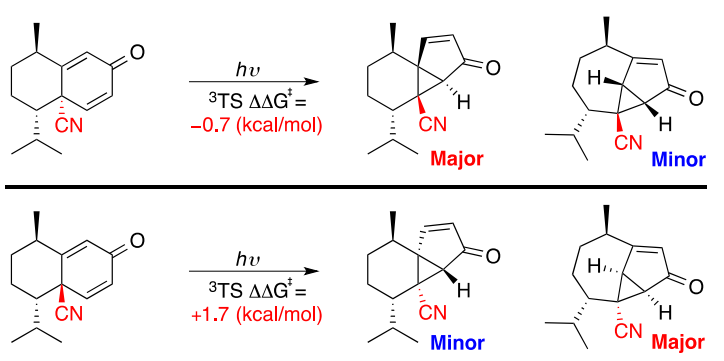

\begin{abstract}
Combined experimental and computational efforts have demonstrated the utility of divergent photocyclization/1,4sigmatropic rearrangement reactions for developing a general strategy toward the synthesis of cubebane-, spiroaxane-, and guaianetype sesquiterpenes and related analogs. The configuration of the bridgehead substituent, the choice of solvent, and the wavelength of irradiation all impact diastereoselectivity in this tandem reaction process.
\end{abstract}

Based on our interest in identifying natural products that interact with transient receptor potential channels, ${ }^{1}$ we required alternative strategies to access cubebane-, guaiane-, and spiroaxane sesquiterpene frameworks for the synthesis of analogs (Scheme 1, 4-6). Inspired by the well-known rearrangement of $\alpha$-santonin to lumisantonin, and related applications in synthesis, ${ }^{2}$ we aimed to establish a general strategy to access the functionalized tricyclic cores $(\mathbf{2}, \mathbf{3})$ using the tandem photocyclization/1,4-sigmatropic rearrangement sequence. The $[1,4]-$ sigmatropic-rearrangement (1,4-SR) reaction has intrigued synthetic chemists for decades but has been relatively underutilized in organic synthesis compared to other rearrangement reactions. ${ }^{3}$ The rich chemistry of divinyl ketones is well known from elegant work on Nazarov chemistry to generate complex cyclopentanones $^{4}$ and the related acid-catalyzed dienone-phenol rearrangement has been investigated extensively. ${ }^{5}$ Oxyallyl cation intermediates generated from irradiation of monocyclic dienones have been used to concisely generate complex polycylic frameworks and have been examined computationally. ${ }^{6}$ Central to our synthetic strategy is an understanding of the impact that existing stereocenters have on the regio- and stereochemical outcome of the tandem reaction. The bridgehead substituent (Scheme 1, 1-X) plays a key role in the rearrangement of fused ring systems by dictating the stereochemical outcome of the initial photo cyclization reaction. In santoninderived syntheses, a methyl substituent is utilized at the bridgehead position imposing severe limitations on subsequent functionalization. ${ }^{2}$ Balancing substituent stability with the ability to be removed under reductive reaction conditions, we selected the nitrile moiety as a versatile bridgehead functional group. From tetrahydrocarvone 7 , the nitrile
Scheme 1. Top: Photomediated rearrangement of $\alpha$-santonin Bottom: Retrosynthesis for the divergent syntheses of sesquiterpene frameworks using tandem reaction.<smiles>CC1=C2[C@@H]3OC(=O)[C@H](C)[C@H]3CC[C@@]2([18OH])C=CC(=O)C1C</smiles><smiles>[Y]C1=CC2([X])C(=CC1=O)C(C)CC(C)C2C(C)C(C)C1CC(C)CC12CCC(C)C21CC(C(C)C)CCC1C</smiles>

moiety was introduced using tosyl cyanide and LDA (8), followed by annulation using methyl vinyl ketone and catalytic sodium methoxide (9:10, Scheme 2). Dehydration of 9 to form 
Scheme 2. (a) $p$-Tol- $\mathrm{SO}_{2} \mathrm{CN}, \mathrm{LDA},-78^{\circ} \mathrm{C}, 85 \%$, (b) $\mathrm{NaOMe}$, methylvinylketone, 64\% (5.3:1), (c) i) TFAA, DIPEA, 93\%; ii) TMSOTf, $\mathrm{NEt}_{3}$, iii) $\mathrm{Pd}(\mathrm{OAc})_{2}, 77 \%$ or $\mathrm{NBS} ; \mathrm{LiCO}_{3}, 85 \%$.

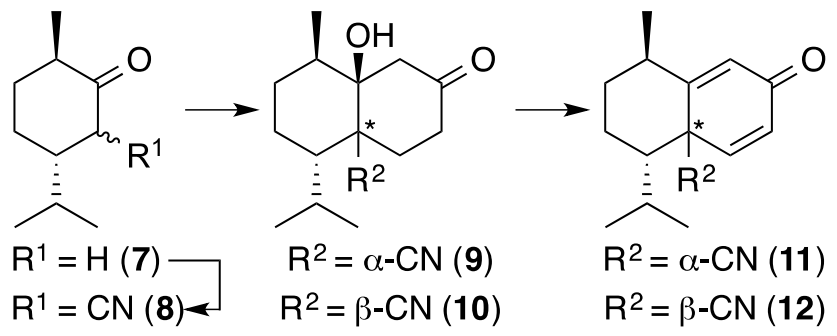

the $\alpha, \beta$-unsaturated ketone, was followed by formation of dienone 11 via halogenation and elimination (85\% over three steps). In order to obtain gram quantities of 10, a revised synthetic strategy was also devised from $(R)$-carvone ${ }^{7,8}$ (See Supporting Information (SI) for details).Conversion of $\mathbf{1 0}$ to the divinylketone $\mathbf{1 2}$ occurred in a similar fashion however Saegusa oxidation was required as the analogous halogen elimination strategy used for $\mathbf{9}$ gave low yields of the desired product $(5 \%)$. With the key precursors in hand, the central photorearrangement/1,4-SR sequence could be explored. Irradiation conditions of $\mathbf{1 1}$ and $\mathbf{1 2}$ were evaluated by varying solvents and wavelengths of light (monitoring by ${ }^{1} \mathrm{H}-\mathrm{NMR}$ spectroscopy). Exposure of 11 in benzene to visible light $(400-700 \mathrm{~nm})$ provided low conversion and selectivity to 13:14 that improved slightly using UV-A (315-400 nm) or UV-B light $(280-315 \mathrm{~nm}$, Scheme 3, entry 1-3). To minimize the amount of degradation byproducts observed on increased scale, it was necessary to recycle starting material through the reaction conditions (entries 4,5 ). Changing the solvent to acetonitrile had a marked effect of reaction rate and selectivity. A consistent improvement in the conversion of starting material was observed with increasing the wavelength from visible to UV-C light (UV-C: 235-280 nm; entries 6-10). Contrary to the reactivity of 11, the tandem reaction of $\mathbf{1 2}$ in benzene was highly selective for $\mathbf{1 6}$ regardless of wavelength of light that was used (entries 11-13). The reaction selectivity of $\mathbf{1 2}$ to $\mathbf{1 6}$ was essentially unaffected by C6-substituents as incorporation of a halogen produced the respective bromo-derivative ${ }^{9}$ of 16 (entries 14,15). The 6methyl- and 6-cyano- substituents formed the respective derivatives of 16, containing adjacent chiral quaternary centers, in good yield using visible light (entries 16, 17). Upon switching the solvent to acetonitrile, $\mathbf{1 5}$ could be observed in the course of the irradiation with visible light however, the ratio of 15:16 decreased until only $\mathbf{1 6}$ remained after full conversion of starting material (entries 18-20). Similar results are obtained using UV-A and UV-B requiring significantly shorter reaction times (entries 21-23) while UV-C was optimal for obtaining 15 (entries 24-26). Extending reaction times using UV-C light led to complex mixtures of degradation byproducts. Although substrate configuration plays a major role in the outcome of the tandem reaction process, the choice of solvent and wavelength of irradiation have a significant impact on the regioselectivity observed in the resulting products. A similar dependence of wavelength on product selectivity in photochemical reactions has been previously reported..$^{10}$ After the tandem rearrangement sequence, the choice of retention or fissure of the cyclopropane moiety determines the natural product framework to be obtained. Reduction of $\mathbf{1 3}$ was accomplished by hydrogenation with $\mathrm{Pd} / \mathrm{C}$ to produce 17 (Scheme 4). Generation of the spirocycle 18 occurred by reductive ring-opening of 17 using sodium
Scheme 3. Optimization of irradiation conditions (see SI for details) ${ }^{a}$ Type of light bulb used. ${ }^{b}$ Hours irradiated. ${ }^{c}$ Ratio based on crude ${ }^{1} \mathrm{H}-\mathrm{NMR}$ spectra. No ratio indicates maximum conversion to isolated product. ${ }^{d}$ Yield of major product unless indicated. ${ }^{e}$ Benzene solvent. ${ }^{f 5-70 ~} \mathrm{mg}$ scale. ${ }^{g} 480 \mathrm{mg}$ scale, yields based on 2 recycles. ${ }^{h}$ Yield of minor product. ${ }^{i}$ Acetonitrile solvent. ${ }^{j} 150$ - $180 \mathrm{mg}$ scale. ${ }^{k}$ Low conversion with extensive product degradation observed.
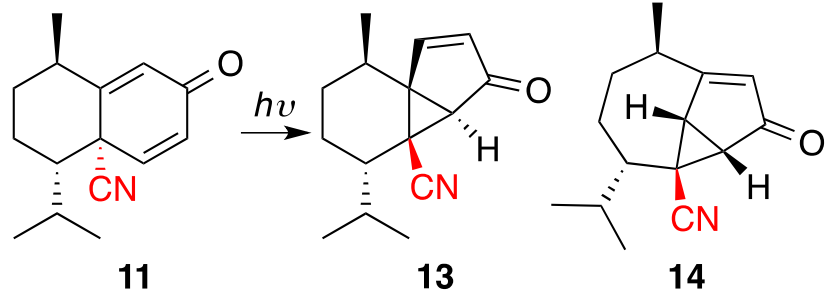

$\begin{array}{ccccc}\text { entry } & \text { light }^{a} & \begin{array}{c}\text { time }^{b} \\ \text { (h) }\end{array} & \begin{array}{c}13: 14^{c} \\ ([13+14]: 11)\end{array} & \begin{array}{c}\text { isolated } \\ \text { yield }(\%)^{d}\end{array} \\ 1^{e, f} & \text { visible } & 24 & 2: 1(5: 95) & -- \\ 2^{e, f} & \text { UV-A } & 0.5 & 2: 1(24: 76) & -- \\ 3^{e, f} & \text { UV-B } & 2 & 3: 1(20: 80) & -- \\ 4^{e, g} & \text { UV-B } & 4 & 3: 1 & 56 \\ 5^{e, g} & \text { UV-B } & 4 & 3: 1 & 13^{h} \\ 6^{f, i} & \text { visible } & 2 & 4: 1(5: 95) & -- \\ 7^{f, i} & \text { UV-A } & 2 & 3: 1(26: 74) & -- \\ 8^{f, i} & \text { UV-B } & 2 & 3: 1(46: 54) & -- \\ 9^{f, i} & \text { UV-C } & 0.7 & 9: 1(98: 2) & -- \\ 10^{i, j} & \text { UV-C } & 2 & 9: 1 & 81\end{array}$

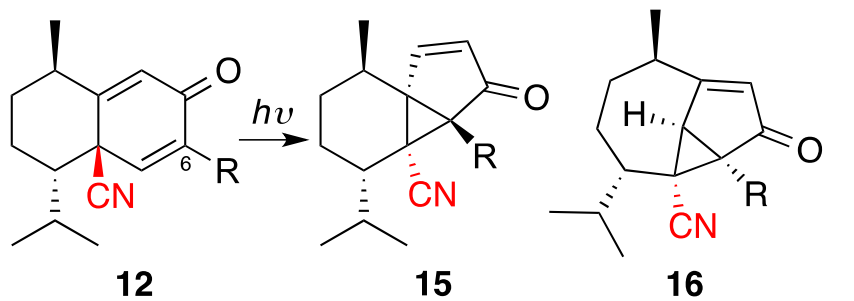

$\begin{array}{cccccc}\text { entry } & \mathrm{R} & \text { light }^{a} & \begin{array}{c}\text { time }^{b} \\ (\mathrm{~h})\end{array} & \begin{array}{c}15: 16^{c} \\ ([15+16]: 12)\end{array} & \begin{array}{c}\text { isolated } \\ \text { yield }(\%)^{d}\end{array} \\ 11^{e, f} & \mathrm{H} & \text { visible } & 100 & 0: 1 & 89 \\ 12^{e, f} & \mathrm{H} & \text { UV-A } & 2 & 0: 1(90: 10) & -- \\ 13^{e, f} & \mathrm{H} & \mathrm{UV}-\mathrm{B} & 2 & 0: 1(38: 62) & -- \\ 14^{e, f} & \mathrm{Br} & \text { visible } & 100 & 0: 1(16: 84)^{k} & -- \\ 15^{e, f} & \mathrm{Br} & \mathrm{UV}-\mathrm{A} & 3 & 0: 1 & 32^{k} \\ 16^{e, f} & \mathrm{CH}_{3} & \text { visible } & 100 & 0: 1 & 89 \\ 17^{e, f} & \mathrm{CN} & \text { visible } & 100 & 0: 1 & 88 \\ 18^{f, i} & \mathrm{H} & \text { visible } & 20 & 1: 9(53: 47) & -- \\ 19^{f, i} & \mathrm{H} & \text { visible } & 44 & 1: 19(75: 25) & -- \\ 20^{f, i} & \mathrm{H} & \text { visible } & 80 & 0: 1(99: 1) & -- \\ 21^{f, i} & \mathrm{H} & \mathrm{UV}-\mathrm{A} & 3 & 0: 1(100: 0) & -- \\ 22^{f, i} & \mathrm{H} & \text { UV-A } & 9 & 0: 1 & 79 \\ 23^{f, i} & \mathrm{H} & \text { UV-B } & 2 & 1: 10(65: 35) & -- \\ 24^{f, i} & \mathrm{H} & \text { UV-C } & 0.8 & 1: 4.5(93: 7) & -- \\ 25^{i, j} & \mathrm{H} & \text { UV-C } & 3 & 1: 4.5 & 47 \\ 26^{i, j} & \mathrm{H} & \text { UV-C } & 3 & 1: 4.5 & 14^{h}\end{array}$


Scheme 4. Top: Reduction and ring-opening of $\mathbf{1 3}$ followed by reductive decyanation to generate spiroaxane- or cubebane-type frameworks. Bottom: Synthesis of cubebol.

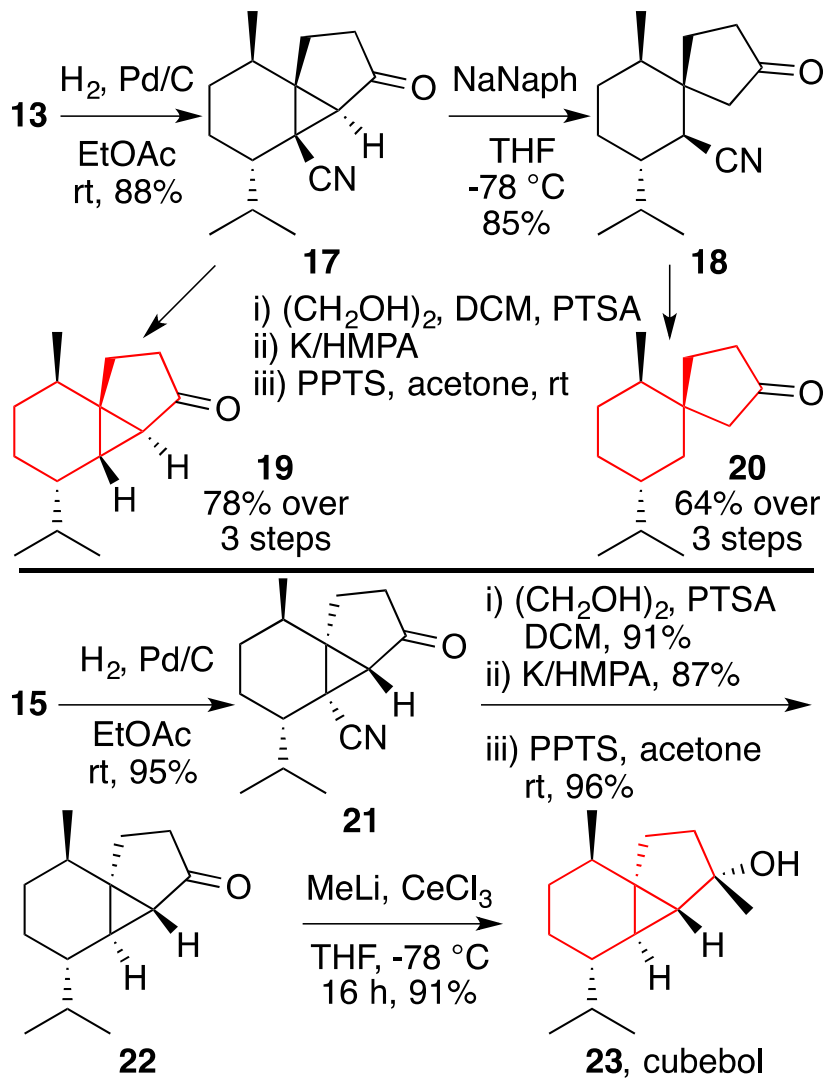

napthalide at low temperature. ${ }^{11}$ Following literature precedent for decyanation reactions, ketone $\mathbf{1 8}$ was protected as the cyclic acetal before reacting with potassium/HMPA. ${ }^{12}$ Removal of the acetal under mildly acidic conditions generated the spiroaxane-like compound 20. Compound 17 can also be directly protected to form a cyclic acetal and exposure to dissolving metal conditions followed by acid treatment completes the decyanation reaction to maintain the cubebane-like ring system of known compound 19. ${ }^{13}$ Utilizing an identical strategy, rearrangement product 15 was hydrogenated to produce 21 in high yield. Acetal formation, decyanation, and acid treatment to ketone 22 then allowed clean conversion to the natural product cubebol (23) by treatment with $\mathrm{MeLi}$ and $\mathrm{CeCl}_{3} \cdot{ }^{13,14}$

Scheme 5. Reduction and ring-opening of $\mathbf{1 6}$ followed by decyanation to form guaiane-type scaffold.

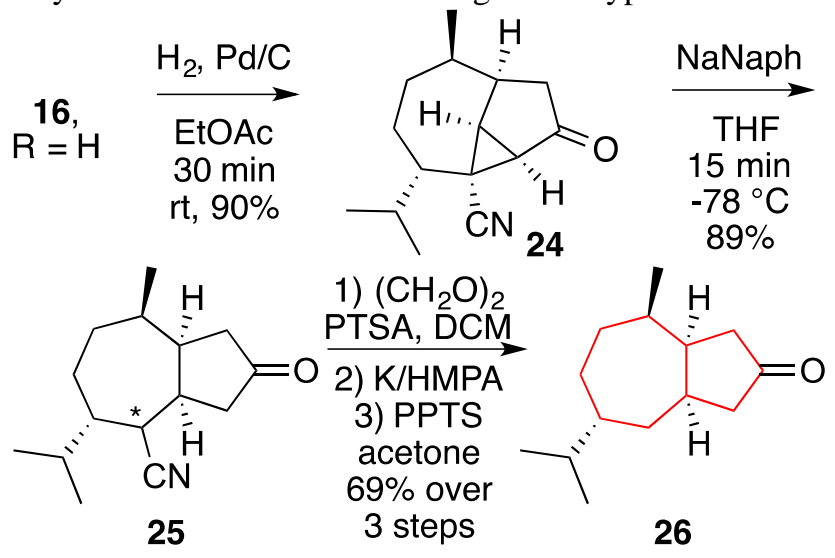

Hydrogenation of 16, produced tricyclic compound 24 (Scheme 5). Reductive ring opening using sodium naphthalide generated 25 as a separable, but inconsequential mixture of diastereomers $(85: 15)$ as a three-step sequence produced the decyanated, guaiane-type compound $\mathbf{2 6}$. The decyanation of tertiary nitrile $\mathbf{2 4}$ occurs using analogous conditions to those used for $\mathbf{1 7}$ and 21 (see SI for details).

Given the utility of tricyclic frameworks 13-16 as intermediates in complex molecule synthesis, we investigated the competing mechanisms computationally (Figure 1). ${ }^{15}$ The M06-2X exchange-correlation functional was used for all geometry optimizations, and the Karlsruhe def2-SZVP basis set for all elements. Single point energetics were further refined with a larger def2-TZVP basis set and implicit SMD description of acetonitrile. ${ }^{16}$ The uM06-2X functional has been used previously by Houk and co-workers to describe the triplet PES of the di- $\pi$ methane rearrangement of dibenzobarrelenes, and gives comparable results to multi-configurational (MCSCF) calculations. ${ }^{17}$ In accord with Zimmerman's seminal experimental findings, ${ }^{18}$ C3-C5 bond formation in triplet states of cycloheaxadienones 11 and 12 is facile (barriers of 3.6 and $6.1 \mathrm{kcal} / \mathrm{mol}$, respectively). Recent MCSCF computations on the santonin-lumisantonin rearrangement show that intersystem crossing (ISC) to the singlet state can occur either at this stage, or following subsequent C-C cleavage. ${ }^{19}$ The formation of Woodward-Hoffmann disallowed products $\mathbf{1 4}$ and $\mathbf{1 6}$ is inconsistent with singlet ground state reactivity (i.e. a Zimmerman type $A$ zwitterion), and suggests ISC occurs after C-C cleavage. Therefore, assuming that cyclopropyl ring-opening takes place in the triplet-state we obtained competing transition structures (TSs) in which the cleavage of either $\mathrm{C}-\mathrm{C}$ bond takes place to give the two product skeletons. The activation barriers for these TSs are all feasible, and most importantly, are consistent with the observed switch in product selectivity obtained from 11 and 12: the computed selectivity is $3.3: 1\left(\Delta \Delta \mathrm{G}^{\neq} 0.7 \mathrm{kcal} / \mathrm{mol}\right)$ in favor of cubebane $\mathbf{1 3}$ and 1:12.6 $\left(\Delta \Delta \mathrm{G}^{\neq} 1.7 \mathrm{kcal} / \mathrm{mol}\right)$ in favor of guaiane $16{ }^{20}$ This computed switch in selectivity was independent of the level of theory used: uwB97XD, uB3LYP-D3(BJ) and uB2-PLYP single-point energies for the TSs with the def2-TZVP basis set all favor the formation of cubebane 13 (by $0.2-0.7 \mathrm{kcal} / \mathrm{mol}$ ) and guaiane 16 (by $1.6-1.7 \mathrm{kcal} / \mathrm{mol}$ ). The triplet pathway for each diastereomer is thus predicted to occur with opposite selectivity. Nevertheless, excited and ground singlet-state reactivity is also plausible for both diastereomers. The cyclopropane-opening TSs (A-B, A-C, D-E, D-F) lead to triplet diradical intermediates which, following ISC, were found to evolve barrierlessly to singlet products. Alternative diastereomers to those observed experimentally were investigated for these stepwise rearrangements, although in every case these were substantially disfavored by more than $25 \mathrm{kcal} / \mathrm{mol}$. In addition, a singlet, concerted [1,4]-sigmatropic rearrangement was also found for the formation of cubebane product in each case: although this pathway could take place if ISC occurs earlier, these TSs were found to be less stable than the triplet TSs discussed above. Our combined experimental and computational efforts indicate that cyclohexyl substituents exert a controlling steric influence on product selectivity. In the favored TS A-C, the cyclohexyl ring is half-chair-shaped with pseudoequatorial $\mathrm{Me}$ and ${ }^{i} \mathrm{Pr}$ groups; in the disfavored TS D-F, a twist-boat conformation results in which there is an unfavorably small contact $(2.17 \AA)$ between the cyclopentadienyl and ${ }^{i} \operatorname{Pr}$ substituents (see SI). We 

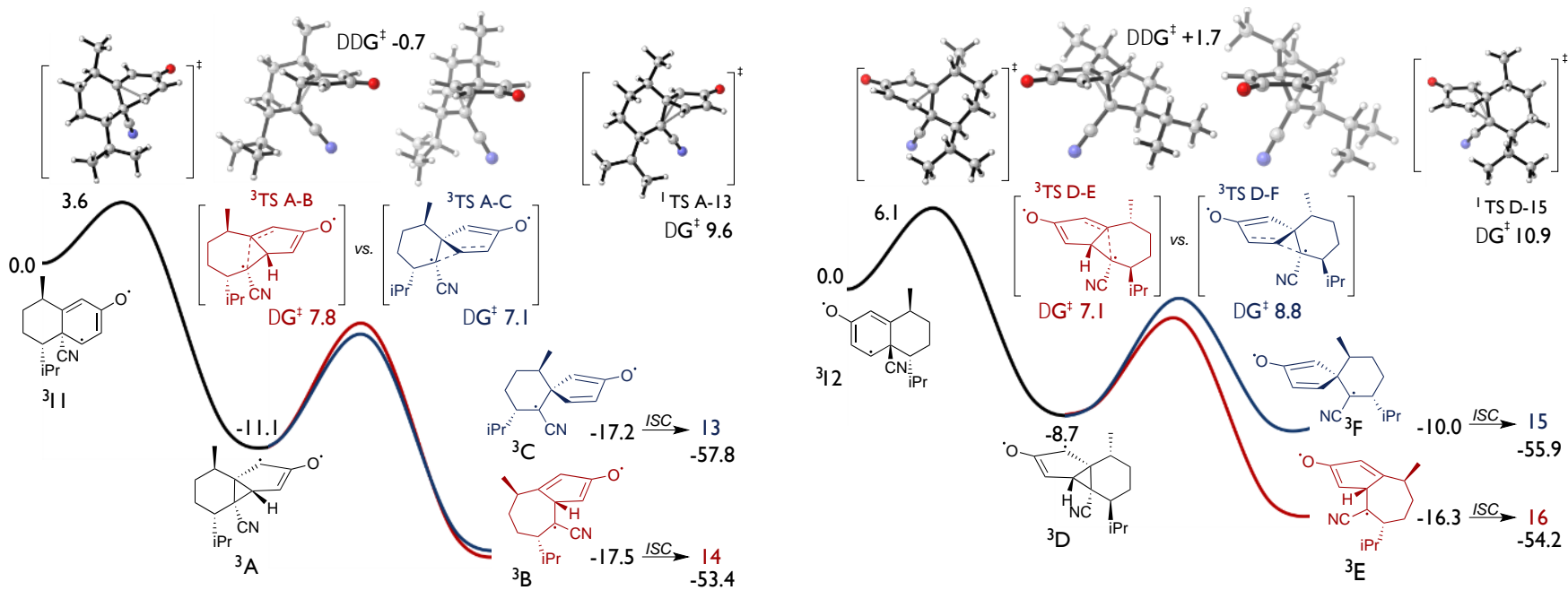

Figure 1. Rearrangements of 11 and 12. SMD-uM062X/def2-TZVP//uM062X/def2-SVP relative Gibbs energies (kcal/mol).

speculate that the increased formation of cubebane-type products at lower wavelengths may occur due to $\mathrm{C}-\mathrm{C}$ formation in an excited singlet state, and that a singlet $[1,4]$-rearrangement could also bypass the involvement of the triplet pathway. The tandem photo-cyclization/1,4-sigmatropic rearrangement strategy is a viable method to access densely functionalized polycyclic frameworks found in cubebane-, spiroaxane-, and guaianetype sesquiterpenes. Computational evidence is consistent with singlet and triplet mechanisms competing to form reaction products depending on conformational effects of the substituents. With new insights gained from the tandem cyclizationrearrangements of $\mathbf{1 1}$ and $\mathbf{1 2}$, we are focusing our efforts on developing novel methods to further control selectivity.

\section{ASSOCIATED CONTENT}

\section{Supporting Information}

Experimental procedures, ${ }^{1} \mathrm{H}$ and ${ }^{13} \mathrm{C}$ spectra for all new compounds. X-ray crystal structures of compounds $9,10,14,16-\mathrm{H}$, 16-CN, and 17. Computational details, Cartesian coordinates and absolute energies.

\section{AUTHOR INFORMATION}

\section{Corresponding Author}

* email: dderksen@ucalgary.ca

\section{Author Contributions}

All authors have given approval to the final version of the manuscript.

\section{ACKNOWLEDGMENT}

D.J.D. holds the Alberta Children's Hospital Foundation Junior Chair in Medicinal Chemistry and is supported by funding from the Alberta Children's Hospital Research Institute and the University of Calgary.

\section{REFERENCES}

(1) LeGay, C. M.; Gorobets, E.; Iftinca, M.; Ramachandran, R.; Altier, C.; Derksen, D. J. Org. Lett. 2016, 18, 2746-2749.

(2) a) Bach, T.; Hehn, J. P. Angew. Chem. Int. Ed. 2011, 50, 10001045. b) Blay, G.; Bargues, V.; Cardona, L.; Collado, A. M.; García, B.; Muñoz, M. C.; Pedro, J. R. J. Org. Chem. 2000, 65, 2138-2144. c) Greene, A. E.; Edgar, M. T. J. Org. Chem. 1989, 54, 1468-1470. d) Edgar, M. T.; Greene, A. E.; Crabbe, P. J. Org. Chem. 1979, 44, 159-
160. e) Marshall, J. A.; Johnson, P. C. J. Org. Chem. 1970, 35, $192-$ 196. f) White, E. H.; Marx, J. N. J. Am. Chem. Soc. 1967, 89, 55115513.

(3) a) Tantillo, D. J. Acc. Chem. Res. 2016, 49, 741-749. b) Houk, K. N.; Li, Y.; Evanseck, J. D. Angew. Chem. Int. Ed. 1992, 31, 682708. c) Padwa, A.; Bur, S. K. Tetrahedron 2007, 63, 5341-5378.

(4) a) Tius, M. A. Chem. Soc. Rev. 2014, 43, 2979-3002. b) Spenser III, W, T.; Vaidya, T.; Frontier, A. J. Eur. J. Org. Chem. 2013, 3621-3633. c) Vaidya, T.; Eisenberg, R.; Frontier, A. J. ChemCatChem 2011, 3, 1531-1548. d) Marx, V. M.; Burnell, D. J. J. Am. Chem. Soc. 2010, 132, 1685-1689. e) Nakanishi, W.; West, F. G. Curr. Opin. Drug. Discov. Devel. 2009, 12, 732-751. f) Tius, M. A. Eur. J. Org. Chem. 2005, 2193-2206.

(5) a) Vitullo, V. P.; Grossman, N. J. Am. Chem. Soc. 1972, 94, 3844-3848. b) Schultz, A. G.; Green, N. J. J. Am. Chem. Soc. 1992, 114, 1824-1829. c) Schultz, A. G.; Hardiner, S. A. J. Org. Chem. 1991, 56, 1105-1111.

(6) a) Bos, P. H.; Antalek, M. T.; Porco Jr., J. A.; Stephenson, C. R. J. J. Am. Chem. Soc. 2013, 135, 17978-17982. b) Dauben, W. G.; Hecht, S. J. Org. Chem. 1998, 63, 6102-6107. c) Gómez, I.; Olivella, S.; Reguero, M.; Riera, A.; Solé, A. J. Am. Chem. Soc. 2002, 124, 15375-15384.

(7) Shipe, W. D.; Sorensen, E. J. J. Am. Chem. Soc. 2006, 128, 7025-7035.

(8) Ayad, T.; Genisson, Y.; Batlas, M. Org. Biomol. Chem. 2005, 3, 2626-2631.

(9) Halogenation procedure adapted from: Nicolaou, K. C.; Lim, Y. H.; Becker, J. Angew. Chem. Int. Ed. 2009, 48, 3444-3448.

(10) Stichnoth, D.; Kölle, P.; Kimbrough, T. J. Riedle, E.;VivieRiedle, R.; Trauner, D. Nat. Commun. 2014, 5, 5597-5601.

(11) Magnus, P.; Booth, J.; Diorazio, L.; Donohoe, T.; Lynch, V.; Magnus, N.; Mendoza, J.; Pye, P.; Tarrant, J. Tetrahedron 1996, 52, 14103-14146.

(12) a) Kametani, T. J. Org. Chem. 1982, 47, 2331-2342. b) Kametani, T.; Suzuki, K.; Nemoto, H. J. Am. Chem. Soc. 1981, 103, 2890-2891. c) Rojas, G.; Wagener, K. B. J. Org. Chem. 2008, 73, 4962-4970.

(13) Hodgson, D. M.; Salik, S.; Fox, D. J. J. Org. Chem. 2010, 75, 2157-2168.

(14) a) Tanaka, A.; Tanaka, R.; Uda, H.; Yoshikoshi, A. J. Chem. Soc., Perkin Trans. 1 1972, 1721-1727. b) Piers, E.; Britton, R. W.; de Wall, W. Can. J. Chem. 1971, 49, 12-19. c) Fürstner, A.; Hannen, P. Chem. Eur. J. 2006, 12, 3006-3019. d) Fehr, C.; Galindo, J. Angew. Chem., Int. Ed. 2006, 45, 2901-2904.

(15) Calculations were performed with Gaussian09 rev. D01: see SI for full details. 
(16) a) Zhao, Y.; Truhlar, D. G. Theor. Chem. Acc. 2008, 120 215-241; b) A. V. Marenich, C. J. Cramer, and D. G. Truhlar J. Phys. Chem. B 2009, 113, 6378-6396.

(17) a) Matute, R. A.; Houk, K. N. Angew. Chem. Int. Ed. 2012, 51, 13097-13100.; b) Matute, R. A.; Garcia-Garibay, M. A.; Houk, K. N. Org. Lett. 2014, 16, 5232-5234; c) Jiménez-Osés, G.; Liu, P.; Matute, R. A.; Houk, K. N. Angew. Chem. Int. Ed. 2014, 53 , 86648667.
(18) Zimmerman, H. E.; Pasteris, R. J. J. Org. Chem. 1980, 45, 4864-4876.

(19) Chen, X.; Rinkevicius, Z.; Luo, Y.; Ågren, H.; Cao, Z. ChemPhysChem 2012, 13, 353-362.

(20) Peng, Q.; Duarte, F. Paton, R. S. Chem. Soc. Rev. 2016, 45, 6093-6107. Selectivities were obtained from application of TST; focussing solely on the triplet-state TSs. 